\title{
Young and Poor: The Well-Being of Adolescent Girls Living in Families Receiving Temporary Assistance for Needy Families Program
}

\author{
Roger A. Boothroyd, Ph.D., ${ }^{1,6}$ Angela Gomez, Ph.D., ${ }^{2}$ \\ Mary I. Armstrong, Ph.D., ${ }^{3}$ Diane Haynes, M.S., ${ }^{4}$ \\ and Rhonda Ort, B.S. ${ }^{5}$
}

We present our findings on the current well-being of 125 adolescent girls living in families receiving Temporary Assistance for Needy Families Program (TANF) in terms of their health, mental health, and substance abuse status, academic performance, and teenage behaviors. This mixed-method study included separate structured face-to-face interviews with each adolescent and her mother. In addition, 20 daughters were randomly selected and completed more in-depth qualitative interviews. The findings suggest that generally the daughters were in good physical health although they reported mental health problems at about twice the rate that would be expected in a general pediatric sample. Further, about 3-5\% of the daughters had a potential serious substance abuse problem. With respect to school, about $28 \%$ were not currently attending school although the majority of daughters who were attending school maintained a $B$ average or better. Nearly two-thirds of the daughters reported being sexually active and almost $17 \%$ of the adolescents had children of their own, much higher than the $2.9 \%$ national rate of girls in this age cohort. While many of these daughters' life circumstances may

\footnotetext{
${ }^{1}$ Associate Professor, Department of Mental Health Law and Policy, Louis de la Parte Florida Mental Health Institute, University of South Florida, Tampa, FL.

${ }^{2}$ Assistant in Research, Department of Child and Family Studies, Louis de la Parte Florida Mental Health Institute, University of South Florida, Tampa, FL.

${ }^{3}$ Director, Department of Child and Family Studies, Division of State and Local Support, Louis de la Parte Florida Mental Health Institute, University of South Florida, Tampa, FL.

${ }^{4}$ Coordinator, Statistical Research, Department of Mental Health Law and Policy, Louis de la Parte Florida Mental Health Institute, Tampa, FL.

${ }^{5}$ Coordinator of Research Programs and Services, Department of Mental Health Law and Policy, Louis de la Parte Florida Mental Health Institute, Tampa, FL.

${ }^{6}$ Correspondence should be directed to Roger A. Boothroyd, Department of Mental Health Law and Policy, Louis de la Parte Florida Mental Health Institute, University of South Florida, 13301 Bruce B. Downs Blvd., Tampa, FL 33612-3807; e-mail: boothroy@fmhi.usf.edu.
} 
not be optimal, findings from both the quantitative and qualitative interviews with both mothers and daughters indicate that these daughters possess many strengths, abilities, and desires.

KEY WORDS: adolescent girls; well-being; poverty; welfare; TANF.

The passage of the Personal Responsibility and Work Opportunity Reconciliation Act (PRWORA, P.L. 104-193) in 1996 dramatically altered welfare in America. Known as the Temporary Assistance for Needy Families Program (TANF), the intent of the legislation was to assist recipients in becoming economically self-sufficient through mandated work requirements for recipients and supportive services to assist them in this welfare to work transition. Among these were transportation services, child care programs, and vocational training. As Congress continues debate on TANF reauthorization, several proposed changes could have an important impact on welfare recipients and their families. One proposal would require those receiving cash assistance to participate in federally defined activities (e.g., work) for at least $40 \mathrm{hr}$ per week, up from $20 \mathrm{hr}$. Another would decrease states' participation rate exclusions, therefore increasing the proportion of welfare recipients needing to meet these requirements.

Much of the early research on welfare reform focused on maternal outcomes such as employment and earnings with little emphasis placed on children (Children Now, 1998). The research involving children focused on younger children, considered most vulnerable to mothers' work requirements with less attention placed on adolescents (Gennetian et al., 2002). Several recent studies suggest that adolescents may be negatively impacted by welfare reform initiatives resulting in poorer school performance, increased behavioral problems, and higher rates of drinking, smoking, drug use, and delinquent behavior.

This emerging body of research on the impact of welfare reform on adolescents raises some cause for concern. Bloom et al. (2000) study of the Florida's Family Transition Program found adolescents had poorer school outcomes and increased behavioral problems. Zaslow et al. (2001) review of experimental studies in various states, including Florida, found ". . . fairly consistent and unfavorable patterns of impacts for adolescents across work programs and economic impact patterns" (p. 89). Gennetian et al. (2002) meta-analysis of eight randomized control studies of adolescent outcomes found those in work program performed significantly worse than those in the control groups. Poorer outcomes included lower school performance, increased repeating of grades and receipt of specialized school services. They concluded there are "... worrisome detrimental impacts on some, but by no means all, of the adolescent outcomes measured in these studies" (p. 22). Of further concern is the fact that findings from some studies suggest that these negative effects may be even more devastating to girls (Taylor, 2000). 
The purpose of this longitudinal, mixed-method study was to assess the current well-being of adolescent daughters living in families receiving TANF in terms of their health status, academic performance, and social behaviors and to identify what changes, if any, transpired in these daughters' lives over time (e.g., leaving school or moving out of the house).

\section{METHOD}

This two-phase longitudinal study used a mixed-method approach to expand the breadth of inquiry (Caracelli \& Greene, 1993) and better understand the experiences of these daughters. In Phase 1, separate structured face-to-face interviews were conducted with 125 TANF mothers and their daughters to assess the daughters' well-being. Phase 2 involved in-depth open-ended interviews done with a random sample of 20 daughters from Phase 1 to explore in greater detail how they were doing and what factors related to their well-being. The findings reported are based on 2 years of data (i.e., 2002 and 2003) collected approximately 1 year apart.

\section{Study Questions}

The study sought to determine how these daughters were doing in terms of their (1) health, mental health, and substance abuse status, (2) academic performance, and (3) social behaviors.

\section{Subjects}

At the start of the study (i.e., 2002), 125 mothers receiving TANF and their adolescent daughters ages 13-17 were identified from Florida Medicaid eligibility data. All lived in a five-county region in Florida with $56 \%$ of the mothers and daughters residing in urban areas and $44 \%$ in rural areas. Mothers' ages ranged from 30 to 53 , averaging 38.4 years old $(S D=4.99$ ). Daughters averaged $151 / 2$ years old $(S D=.99)$, ranging from 13 to 17 . Regarding race/ethnicity, $40.7 \%$ of the mothers were white, $38.2 \%$ Black/African American, and 21.1\% Hispanic. Daughters were more culturally diverse as $33.6 \%$ were white, $40.8 \%$ Black/African American, and 25.6\% Hispanic. Most mothers were divorced, separated, or widowed $(54.4 \%)$ or never married $(32.8 \%)$; only $12.8 \%$ were married or living with someone. None of the daughters were married. Over half of the mothers had not completed high school. Several notable changes occurred between 2002 and 2003. In terms of housing, the percentage of mothers living with family or friends increased from $12.8 \%$ in 2002 to $22.6 \%$ in 2003 . In year two, $12.6 \%$ of the daughters were living on their own and one adolescent had gotten married. 


\section{Attrition Rates}

In 2003, 112 mothers and their daughters $(89.6 \%)$ were reinterviewed. One mother was interviewed without her daughter $(.8 \%)$ and four daughters without their mothers (3.2\%). Data were obtained on 117 of the original 125 daughters $(93.6 \%)$. Phase 2 interviews were conducted with 18 of the 20 adolescents $(90.0 \%)$. No significant differences on any demographic variables were noted between mothers and daughters who were reinterviewed and those lost to attrition.

\section{Instruments}

The Phase 1 structured interview included psychometrically tested respondent self-report health, mental health, and substance abuse status measures, school performance, and social behaviors. Adolescents' health status was assessed with the SF-12 (Keller, Kosinski, \& Ware, 1996) a 12-item measure. The Pediatric Symptom Checklist (Jellinek, Murphy, \& Burns, 1986), a 30-item screen assessed daughters' mental health status. The Simple Screening Instrument (Winters, \& Zenilman, 1994) monitored their alcohol and other drug use. Questions about school performance and social behaviors were adapted from the Massachusetts Youth Risk Behavior Survey (Goodenow, 1999) and a U.S. Census Bureau survey (Hess, \& Rothgeb, 1999).

Phase 2 involved a semi-structured interview. The interviews addressed similar issues as those in Phase 1 but involved more comprehensive open-ended questions to better understand the personal, familial, and environmental factors associated with these daughters' current well-being.

\section{Procedures}

Mother daughter pairs were identified using the Florida Medicaid eligibility data. Letters were mailed to potential participants informing them about the study and that they would be contacted. Individuals not wanting to be contacted were instructed to call a toll free number. Trained field staff contacted eligible mothers and daughters in January 2002, explaining the purpose and scope of the study and inviting their participation. Mothers and daughters willing to participate signed separate informed consents and provided permission to link their interview responses to existing administrative data. In January 2003, letters were mailed to all participants asking them to complete a 1-year follow-up interview. In both years, participating mothers and daughters each received $\$ 40.00$. To protect confidentiality, different staff interviewed the mother and daughter although the same interviewers conducted the initial and follow-up interviews. 
In Phase 2, 20 randomly selected 20 daughters from Phase 1 completed an in-depth qualitative interview. Interviews were taped and transcribed to ensure the accuracy. The same daughters completed a 1-year follow-up interview. In both years interviews were open-ended and explored the daughters' current well-being. The adolescents received $\$ 40.00$ for completing these interviews. Prior to initiating any activities, study procedures were reviewed and approved by the University's Institutional Review Board to ensure that participants' rights were protected.

\begin{abstract}
Analysis
Phase 1 analyses are largely descriptive in nature and intended to address the basic questions regarding the current well-being of these daughters. Comparative (i.e., inferential) analyses were performed to assess changes between responses to the 2002 and 2003 interviews and to examine differences between mothers' and daughters' perceptions on similar issues. Data from the Phase 2 qualitative interviews were transcribed and coded following the study's conceptual model and the quantitative analysis to allow data triangulation. Quantitative findings are viewed as important components in the qualitative interpretation and therefore the two approaches blend into one another in the content (House, 1994).
\end{abstract}

\title{
RESULTS
}

In both 2002 and 2003, the current status of these adolescent daughters was examined in three contexts; health-related issues, academic performance, and teenage behaviors.

\section{Health-Related Issues}

In both years, mothers and daughters assessed the daughters' overall health status using a five-point scale ranging from $1=$ "poor" health to $5=$ "excellent" health. The results are presented in Table I. Most daughters were assessed in good to excellent health in both years; however, there was a slight decrease in the proportion of daughters reported by both mothers (89.6-85.7\%) and by themselves (85.6-81.1\%) as being in good to excellent health. The percentage of mothers assessing their daughters' health as fair or poor rose from $10.4 \%$ in 2002 to $14.3 \%$ in 2003 . Similarly, the percentage of daughters reporting their health as fair or poor increased from $14.3 \%$ in 2002 to $18.9 \%$ in 2003 . Despite these increases, daughters' SF-12 scores significantly improved during the year on both the physical $(M=44.8-53.9) t(114)=11.66, p<.001$ and mental health scales $(M=37.5-43.1) t(114)=6.70, p<.001$. The qualitative interviews showed all 
Table I. Daughters Health-Related Status

\begin{tabular}{lccccc}
\hline & \multicolumn{2}{c}{2002} & & \multicolumn{2}{c}{2003} \\
\cline { 2 - 3 } \cline { 5 - 6 } \multicolumn{1}{c}{ Health-related status and needs } & $\begin{array}{c}\text { Mothers } \\
n(\%)\end{array}$ & $\begin{array}{c}\text { Daughters } \\
n(\%)\end{array}$ & & $\begin{array}{c}\text { Mothers } \\
n(\%)\end{array}$ & $\begin{array}{c}\text { Daughters } \\
n(\%)\end{array}$ \\
\hline \% In fair or poor health & $125(10.4)$ & $125(14.4)$ & $112(14.3)$ & $116(18.9)$ \\
$\%$ Above criterion score on PSC & $122(20.3)$ & $125(20.0)$ & $111(18.0)$ & $115(17.4)$ \\
$\%$ Potential substance abuse problems & NA & $123(12.2)$ & NA & $114(13.2)$ \\
$\%$ Unmet physical health need & $87(3.4)$ & $91(4.4)$ & $100(15.0)$ & $66(6.1)$ \\
$\%$ Unmet mental health need & $14(40.0)$ & $6(20.0)$ & $10(30.0)$ & $6(33.3)$ \\
\% Unmet substance abuse need & $1(0)$ & $1(0)$ & & $3(33.3)$ & $0(0)$ \\
\hline
\end{tabular}

daughters in good health with the exception of one who had heart surgery in 2002. They did not report any health-related issues nor feel limited in any way due to health concerns.

Compared to physical health, a higher percentage of daughters were assessed above the criterion score on the Pediatric Symptom Checklist by both mothers and daughters, although the percentage decreased over the year. In 2002, nearly one in five mothers' $(20.3 \%)$ and daughters' (20.0\%) assessments exceeded this threshold, suggesting a possible psychosocial need. These percentages decrease to $18.0 \%$ for mothers and $17.4 \%$ for daughters in 2003 although examination of overall scores on the PSC revealed no significant change between 2002 and 2003 assessments by either the mothers or their daughters. During the in-depth interviews, one of the daughters reported having a learning disability, which impacted her reading skills. She mentioned being classified at school as having a slow learning disability and being assigned to special classes. Another daughter reported having anger control problems. She has received counseling and has been on medication for this condition. However, she feels the medication has not helped because her anxiety increases when she takes it. While both of these conditions are somewhat limiting, these daughters are making efforts to overcome them and do not view them as conditions that limit their ability to succeed in school and have self-fulfilling lives. As shown in Table I, 12.2\% of the adolescents' scores suggested a potential substance abuse need ( $4.1 \%$ a possible serious problem) in 2002. This figure remained relatively constant at $13.2 \%$ (3.4\% a possible serious problem) in 2003. Although the in-depth interviews with the daughters did not reveal any substance abuse related issues, one of the daughters not interviewed in 2003 was reported by one of her ex-neighbors as being on drugs and possibly living in the street.

In 2002, mothers' and daughters' reported low rates of daughters' unmet physical health services needs (i.e., needing services that were not received) (3.4 and $4.4 \%$, respectively) but this increased to $15.0 \%$ for mothers and $6.1 \%$ for daughters in 2003. Although rates of unmet mental health needs were substantially higher relative to physical health in both years, only a small number of 
mothers (2002 $n=14$ and $2003 n=10)$ and daughters ( $n=6$ both years) indicated needs for these services. Few mothers or daughters reported substance abuse service needs although one mother in 2003 noted her daughter had an unmet need.

\section{Academic Performance}

Both the mothers and daughters assessed daughters' educational status in terms of their perceptions of and motivation toward school (e.g., interest in school, desire to continue their education), school behaviors (e.g., participation in extra curricular activities, getting in trouble at school), and academic performance (e.g., grades). Collectively, few changes were observed related to adolescents' educational status between the 2002 and 2003 interviews.

With respect to school enrollment, the status of $80 \%$ of the daughters remained stable during the year. Nearly two thirds (62\%) were attending school at both interviews while $18 \%$ of the daughters were not in school either time. The enrollment status of the remaining $20 \%$ was more dynamic. Eleven of the daughters who were reinterviewed $(9.4 \%)$ and who were not in school at the time of the 2002 interviews were currently attending school. In contrast, 12 daughters (10.4\%) who were in school at the time of the 2002 interviews were no longer in school. The positive aspect of this finding is that for 6 of these 12 daughters the reason they were no longer in school is that they had either graduated from high school or completed their General Education Diplomas (GEDs). Of the remaining 6 adolescents not in school, one got pregnant, two reported no interest in school, one had to work, one reported family problems, and one had been expelled. One of the daughters not in school due to loss of interest participated in the qualitative interviews and reported making an effort to go back to school after realizing the consequences of her decision but was not able to do so. According to her report, the school told her they could not take her back and that she should take the GED classes, which is not what she wanted. When she checked into the GED classes she was told that she could start in the summer or she could start regular school again in the fall. Since she only needed two semesters to complete the three credits she needs to graduate, she decided to start the school year again.

Virtually no change was noted in adolescents' self-report interest in school and their desire to pursue post secondary schooling. In 2002, 97\% of the daughters reported wanting to attend college or vocational school (including those adolescents currently not in school) while in 2003 the figure was 95\%. Among those in school most felt school was preparing them well for the future (92\% compared to $87 \%$ in 2002). Data from the in-depth interviews revealed that although only a limited number of daughters have close relationships with some of their teachers, they value the efforts made by teachers and other school personnel in ensuring they obtain the most benefit out of their academic instruction. These data also showed 
that schools are not providing the guidance adolescents need in order to align their future academic aspirations with their current academic situation. While all of the daughters wanted to pursue higher education, most of them were not aware of the academic requirements needed to enter their fields of interest nor were they aware of issues related to financial aid and scholarships. Mostly they reported that school guidance counselors would provide them with this information in their senior year, without realizing their need to start looking into these issues long before then.

In terms of academic performance, in both years most of the adolescents indicated working hard on their schoolwork (2002 $M=3.49, S E=.78 ; 2003$ $M=3.43 S E=.76$, Note: $4=$ very true). Their grades were similar in both years as the adolescents reported a GPA of 3.01 in 2002 and a GPA of 2.96 in 2003. The slight decrease in 2003 may be related to the fact that daughters are moving into the last years of high school and are exposed to more challenging subjects. This was emphasized by some of the daughters who participated in the in-depth interviews. In both years, most daughters reported completing their homework "almost every day" and noted the importance of doing well in school (2002 $M=2.51, S E=$ $.07 ; 2003 M=2.41 S E=.07$, Note: $3=$ extremely important).

In contrast, the daughters also acknowledged some behavioral issues at school. In 2002, 59\% reported they had received an in- or out-of-school suspension with an average number of suspensions of .55 in the past year. Although not statistically significant, in 2003 these figures increased slightly to $62 \%$ having received a suspension with an average of 1.00. The daughters also reported slight increases in being late for school or classes, skipping classes, and getting into fights. On the positive side, slight but nonsignificant increases were reported for participating in both after school and volunteer activities (both at approximately once a month). Data from the in-depth interviews with the daughters suggest that some of them reported working long hours that contributed to their being tardy or missing school completely. Additionally, some of the daughters noted that increased security in schools following the events of September 11, which required students to wear identification badges and that limit their ability to move freely throughout the school parameters, resulted in increased suspensions. One daughter reported having bomb threats at her school almost on a daily basis.

Generally, mothers' assessments of their daughters' school behavior were consistent with daughters' self-reports. Mothers' assessment of their daughters' GPAs did average about .25 points lower than their daughters' self-assessments and this difference was statistically significant $t(77)=2.05, p<.05$ ). There was also some drop in mothers' perceptions of their daughters' academic progress as in $2002,92 \%$ assessed their daughter's academic performance as average or above as compared to $73 \%$ in 2003 . This difference however, is not statistically significant.

As daughters continue to move through the educational ladder and are reaching their junior and senior years, they are becoming more focused on school activities that may increase their possibilities to transition into higher education upon their high school graduation. For example, one daughter who was completing 
her junior year reported that she had not only improved her grades but was also very committed to the school's band program. She hopes her school achievements and her musical talent will provide her with college scholarship opportunities. Without external financial support it would be very difficult for her family to send her to college. Another daughter expressed an interest in a career in broadcasting and has been volunteering at a local radio station in hopes of increasing the likelihood that she will be able to get into broadcasting school.

\section{Teenage Behaviors}

Mothers and daughters were asked to report on specific behaviors in which teenagers are likely to engage (e.g., running away, smoking, and volunteering). Results from both the 2002 and 2003 mother and daughter interviews are summarized in Table II. In 2002, mothers and daughters reported similar levels regarding the frequency of occurrence on 6 of the 12 behaviors examined. Mothers and daughters reported similar rates on 8 of the 12 behaviors in 2003 .

Dramatic increases were found in the daughters' sexual behavior during the year. Mothers' reports of the daughters' sexual activity increased from $47.9 \%$ in 2002 to $60.7 \%$ in 2003. Daughters' self-reports were similar to their mothers, increasing from $48.8 \%$ in 2002 to $69.0 \%$ in 2003 . As the daughters in this study are growing up, they are beginning to date on a more regular basis, as is to be expected. While several of them reported not being interested in serious dating until they completed higher education, the qualitative interviews showed that some of them were dating regularly or were involved in stable relationships. Not surprisingly, the pregnancy rate also rose among these daughters, increasing from 15.7 to $19.8 \%$. Four additional daughters $(3.2 \%)$ became mothers during the past year raising the rate of teenage mothers among daughters in this sample to $16.7 \%$.

Table II. Teenage Behaviors

\begin{tabular}{lcccc}
\hline \multicolumn{1}{c}{ Behavior } & $\begin{array}{c}\text { Mothers 2002 } \\
(n=125, \%)\end{array}$ & $\begin{array}{c}\text { Mother 2003 } \\
(n=113, \%)\end{array}$ & $\begin{array}{c}\text { Daughters 2002 } \\
(n=125, \%)\end{array}$ & $\begin{array}{c}\text { Daughters 2003 } \\
(n=116, \%)\end{array}$ \\
\hline Ever stolen something & 18.5 & 9.0 & 6.6 & 7.8 \\
Ever destroyed property & 8.8 & 9.9 & 9.6 & 9.6 \\
Ever run away from home & 12.8 & 16.1 & 13.6 & 13.9 \\
Even been in a flight & 21.8 & 22.5 & 6.2 & 27.0 \\
Ever been in a gang & 8.8 & .9 & .8 & 0 \\
Ever smoked & 36.3 & 28.2 & 40.0 & 51.0 \\
Ever ridden with someone & 34.7 & 17.0 & 34.7 & 37.4 \\
$\quad$ drinking & & & & 1.7 \\
Ever drank and driven & .2 & 1.8 & 0 & 69.0 \\
Ever had sex & 47.9 & 60.7 & 48.8 & 19.8 \\
Ever been pregnant & 16.0 & 16.7 & 15.7 & 5.3 \\
Ever had an STD & 12.9 & $\mathrm{NA}$ & 6.6 & 62.0 \\
Ever do volunteer work & 49.5 & 44.7 & 68.7 & \\
m & & & &
\end{tabular}


The adolescents reported meaningful increases in their smoking. In 2002, $40.0 \%$ of the daughters reported smoking; increasing to $51.0 \%$ in 2003 . In contrast, mothers' reports of their daughters' smoking decreased slightly from $36.3 \%$ in 2002 to $28.2 \%$ in 2003. During both interviews, about a third of the daughters reported riding in a car with a friend who had been drinking. In 2002, 25.0\% of the mothers thought their daughters had done this and this percentage declined to $17.0 \%$ in 2003 . The qualitative interviews did not provide significant data in relation to the daughters' smoking and drinking habits. In 2002, one of the daughters mentioned that whenever she went out with her friends they had a designated driver. In 2003 she was pregnant and spending most of her time at home.

Mothers' 2003 reports that their daughters might have stolen something were half the value reported in 2002 (9.0 vs. 18.5\%). The percentage of mothers who believed their daughters might belong to a gang also dramatically decreased from $8.8 \%$ in 2002 to $.9 \%$ in 2003. During both interviews, mothers were less likely to indicate their daughters did volunteer work (49.5 and 44.7\%) compared to their daughters' self-reports (68.7 and 62.0\%).

\section{DISCUSSION}

Findings from the quantitative surveys and in-depth interviews with both mothers and daughters in both years showed that while the daughters' life circumstances may not be optimal, they possess many strengths, abilities, and desires to successfully transition into adulthood. However, many of the daughters also face issues related to health, school, or their behavior that potentially have a significant impact on their ability to make this transition and attain their goals. Data from the 2001, Youth Risk Behavior Surveillance System (YRBSS) conducted by the Centers for Disease Control as well as other studies examining various aspects of adolescents' well-being found in the literature provide useful comparative data for assessing the general well-being of these daughters. The discussion of the findings is organized according to the three domains of interest; health-related issues, academic performance, and teenage behaviors.

Adolescents' scores on the physical health portion of the SF-12 suggest that their health status is similar to what would be expected in a general population. The average score of 53.9 is slightly above general population normative score of 50 on this measure (Keller et al., 1996). In terms of access to physical health care, reported rates of unmet physical health care needs were generally low in the 3-6\% range. This is likely the result of the daughters being in good health and not needing health services as well as many having access to Medicaid coverage.

In contrast, these daughters' scores on the mental health portion of the SF-12 as well as their PSC scores suggest they have higher levels of psychosocial needs 
compared to what would be anticipated in a general population of adolescents. Daughters' average SF-12 mental health score was 43.1, approximately a $.8 S D$ (representing a large effect) below the normative score of 50 (Keller et al., 1996). In addition, approximately $20 \%$ of the daughters fell above the criterion score on the PSC which is nearly twice the rate anticipated in a general pediatric population (Jellinek et al., 1986) and is similar to that found by Boothroyd and Olufokunbi (2001) in their study of children living in families receiving TANF. Unlike physical health, the reported levels of unmet mental health needs (i.e., reported a need for services but did not use services) were substantially higher ranging between 20 and $40 \%$. These higher levels are in part attributable to higher levels of mental health needs and the small number of adolescents and their mothers (i.e., between 6 and 14\%) who perceived these behavioral indicators as reflecting mental health service needs.

Adolescents' scores on the Simple Screen Instrument suggest that potential substance abuse needs might exist for $12-13 \%$ of the daughters in the study. It is important to note however, that more serious substance abuse concerns were only present among $3-5 \%$ of the daughters and that reported unmet substance abuse needs were almost nonexistent. These rates of substance abuse needs found in the present study are lower than the "past year" rate of $24 \%$ reported by Aarons, Brown, Hough, Garland, and Wood (2001) or the $16.3 \%$ reported for females by Johnston, O'Malley, and Bachman (2003) but more closely mirror estimates from several studies involving general populations (Anthony, Warner, \& Kessler, 1994; Kandel et al., 1999). While differences exist across the samples in these studies as well as the methods and criteria used to identify substance abuse problems that can account for the variability in these estimates, the general conclusion is that rates found in this study suggest these daughters do not seem to be at a significant increased risk for substance abuse problems.

Despite higher levels of potential health-related needs among the daughters, these issues were not a central focus of discussion during the qualitative interviews. These issues did not meaningfully define how these adolescents perceive themselves or influence their expectations and desires for the future. Even in the case of one adolescent who last year was home schooled because she was recuperating from open-heart surgery and who continues to receive follow-up treatment, she did not perceive this event as characteristic of herself. She is now back in her regular school, has no physical restrictions, and is looking forward to the future. A 16-year old who shared the challenges of managing her anger and refraining from pulling her hair, which resulted in her placement in an alternative school, did not perceive these challenges as limiting her future. While she noted that she was receiving counseling and taking medication, she perceives things "are getting better" and much of the conversation focused on her family, her success in sports, and finishing school.

In terms of academic performance, significant variability was observed among the daughters. While nearly half of the adolescents attending school in both years 
(51.2\% in 2002 and $45.7 \%$ in 2003) reported grade point average of a B or better, about a third of the daughters (33.6\%) were either not attending school or reported a grade point averages of a D or below. Overall, the $29 \%$ of the adolescents in this study were not attending school is over twice the state rate of $12 \%$ among 16-19-year olds (Annie E. Casey Foundation, 2003), however, the 4.6\% in school but getting Ds and Fs is very similar to the 5.3\% reported by Center for Disease Control's (2003) for Florida females participating in the 2001 Youth Risk Behavior Survey.

In essence the adolescents can be classified in three groups: (1) those performing well academically, with clear academic goals and access to the supports and resources needed to achieve them; (2) those moving in and out of school or not meeting school requirements but who are attempting to remain engaged in the educational process; and (3) those drifting with no academic direction due to lack of interest in school or whose current life circumstances keep them from school.

Daughters in the first group have good grades and the academic and social supports necessary to establish clear goals and to live up to the expectations of their teachers and families. Daughters participating in the qualitative interviews falling into this group were more articulate about their future academic goals, knew what it would take for them to reach them, and had shared their future aspirations with their mothers and some of their teachers. For example, one daughter wanted to be a lawyer, then a judge, and finally sit on the Supreme Court. Her family was supportive of her goals and she was aware it would take her 7 years to become a lawyer and then a couple of years to become a judge and a while longer to get to the Supreme Court. She also knew about some of the schools that offer law degrees and was making sure she had the required credits and grades. Although her family does not have the financial resources to pay for her college education, they know there are resources (i.e., financial aid, scholarships, etc.) available to her and will make every effort to secure them.

Daughters in the second group are either out of school and making an attempt to get back in or are in but experiencing difficulty staying engaged. Two of the daughters who completed qualitative interviews are good examples of these circumstances. One daughter who was attending a school program funded by juvenile justice system for at risk adolescents reached her time limit at the school and found herself out of school. At the time of the 2003 interview she had completed her 9th grade but had no intention to enroll in a regular high school because she felt she was far behind, even though she is only 16 years old. Her plan was to take the GED and she was beginning to look at available Internet and community-based programs. Another daughter who left school when she got pregnant made efforts to get her GED but child care issues prevented her from completing the program. She attended a community program for 4 months but missed more days than the program allowed and was asked to leave. She explained that her absenteeism was due to her sick child and not having anybody to care for him. 
Daughters in the third group are losing interest in school and lack clear academic goals. Only one of the daughters who participated in the qualitative interviews fell into this group. This daughter had dropped out of school when she got pregnant and although she had mentioned her interest in going back or taking the GED, this was not a priority in her life. Her child and her mother's cancer have consumed this daughter's life since she dropped out of school.

Most notable among changes in teenage behaviors was the substantial increase in the percentage of daughters reporting being sexually active. Sexual activity increased from $49 \%$ in 2002 to $69 \%$ in 2003. Not surprisingly, the pregnancy rate also rose among these daughters from 16 to $20 \%$. As was noted by one pregnant daughter during the qualitative interview, her pregnancy was not planned and she reported not wanting to have more children. Overall, four additional daughters $(3.2 \%)$ became mothers during the past year raising the rate of teenage mothers among adolescents in this sample to $16.7 \%$, substantially higher than the rate of $2.9 \%$ reported nationally among teens $15-19$ years old (Annie E. Casey Foundation, 2003) or the 5\% of adolescents in this age cohort reported within the state of Florida (Weitzel \& Shockley, 2002).

\section{CONCLUSIONS}

On a positive note, many aspects of these daughters' lives reflect the same challenges at similar rates as adolescents in the general population. The fact their mothers receive TANF does not place them at significantly greater risk for a poor transition into adulthood. However, much variability exists in the status of these adolescents and where they see themselves in the future.

Two areas in which these daughters' well-being differs from a general population of adolescent girls are the higher prevalence of teenage pregnancy and motherhood and the higher rates of school drop out. Despite this, as was previously noted, having had a child or not being in school is not how these adolescents define themselves. Despite what might be considered increased challenges, most of these daughters have very optimistic views of their futures.

A key factor in these daughters' life trajectories hinges on the extent to which they can access the supports such as child care and transportation to facilitate their ability to pursue their future hopes and aspirations. For a number of the daughters, their current well-being represents a delicate balance between a hopeful outlook for the future and daily challenges associated with being young and poor.

\section{ACKNOWLEDGMENTS}

The study was funded in part through a contract with the Florida Agency for Health Care Administration (Contract \# M0308). 


\section{REFERENCES}

Aarons, G. A., Brown, S. A., Hough, R. L., Garland, A. E., \& Wood, P. A. (2001). Prevalence of adolescent substance use disorders across five sectors of care. Journal of the Academy of Child Adolescent Psychiatry, 40, 419-426.

Annie E. Casey Foundation. (2003). Kids count data book: State profile of child well-being. Baltimore, MD: Author.

Anthony, J. C., Warner, L. A., \& Kessler, R. C. (1994). Comparative epidemiology of dependence on tobacco, alcohol, controlled substances, and inhalants: Basic findings from the National Comorbidity Survey. Experimental \& Clinical Psychopharmacology, 2, 244-268.

Bloom, D., Hendra, R., Kemple, J. J., Morris, P., Scrivener, S., Verma, N., et al. (2000). The Family Transition Program: Final report on Florida's initial time-limited welfare program. New York: Manpower Demonstration Research Corporation. Retrieved, December 30, 2003, from http://www.mdrc.org/publications/20/overview.html

Boothroyd, R. A., \& Olufokunbi, D. (2001). Leaving the welfare rolls: The health and mental health status of current and former welfare recipients. Mental Health Services Research, 3, 119-128.

Caracelli, V. J., \& Greene, J. C. (1993). Data analysis strategies for mixed-method evaluation designs. Educational Evaluation and Policy Analysis, 15, 195-207.

Children Now (1998). Content analysis on welfare reform reporting. Retrieved, July 28, 2003, from http://www.childrennow.org/economics/welfref98/welfarereformshortdoc.html

Center for Disease Control (2003). Youth Risk Behavior Surveillance System: 2001 Information and Results Youth 2001 Online. Washington, DC: Center for Disease Control, National Center for Chronic Disease Prevention and Health Promotion. Retrieved July 29, 2003, from http://www.cdc.gov/nccdphp/dash/yrbs/youth01online.htm

Gennetian, L. A., Duncan, G. J., Knox, V. W., Vargas, W. G., Clark-Kaufman, E., \& London, A. S. (2002). How welfare and work policies for parents affect adolescents: A synthesis of research. New York: Manpower Demonstration Research Corporation.

Goodenow, C. (1999). Massachusetts Youth Risk Behavior Survey. Massachusetts Department of Education. Retrieved June 3, 2003, from http://www.doe.mass.edu/lss/yrbs99/acknowledge.html

Hess, J. C., \& Rothgeb, J. M. (1999). Measuring the impact of welfare reform: Issues in designing the survey of program dynamics questionnaire. Washington, DC: US Census Bureau.

House, E. R. (1994). Integrating the quantitative and qualitative. San Francisco: Jossey-Bass.

Jellinek, M. S., Murphy, J. M., \& Burns, B. J. (1986). Brief psychosocial screening in outpatient pediatric practice. The Journal of Pediatrics, 109, 371-378.

Johnston, L. D., O’Malley, P. M., \& Bachman, J. G. (2003). Monitoring the future national survey results on drug use, 1975-2002: Vol. I. Secondary school students (NIH Publication No. 03-5375) (p. 520). Bethesda, MD: National Institute on Drug Abuse.

Keller, S. D., Kosinski, M., \& Ware, J. E. (1996). A 12-item short-form health survey (SF-12). A construction of scales and preliminary tests of reliability and validity. Medical Care, 32, 220223.

Kandel, D. B., Johnson, J. G., Bird, H. R., Weissman, M. M., Goodman, S. H., Lahey, B. B., et al. (1999). Psychiatric comorbidity among adolescents with substance use disorders: Findings from the MECA study. Journal of the Academy of Child \& Adolescent Psychiatry, 38, 693-699.

Personal Responsibility and Work Opportunity Reconciliation Act of 1996, P.L. 104-193, 110 Stat. 2105.

Taylor, M. H. (2000). The potential impact of gender roles socialization on welfare policy formation. Journal of Sociology and Social Welfare, 27, 35-152.

Weitzel, S., \& Shockley, C. (2002). Florida's children at a glance, 2002. Tampa, FL: University of South Florida, Louis de la Parte Florida Mental Health Institute, Department of Children and Families, Center for the Study of Children's Futures.

Winters, K. C., \& Zenilman, J. M. (1994). The simple screening instrument for alcohol and other drug abuse and infections. Rockville, MD: Substance Abuse and Mental Health Services Administration, Center for Substance Abuse Treatment.

Zaslow, M. J., Moore, K. A., Brooks, J. L., Morris, P. A., Tout, K., Redd, Z. et al. (2001). Experimental studies of welfare reform and children. The Future of Children, 12, 79-95. 